\title{
Prevalence of Social Dietary and Behavioral Risk Factors of Obesity among Primary School Children in Minia Governorate, Egypt
}

\author{
Yosria EL-Sayed Hossein ${ }^{1, *}$, Nabil Mostafa Almarhomy ${ }^{2, *}$ \\ ${ }^{1}$ Community Health Nursing, Faculty of Nursing, Minia University \\ ${ }^{2}$ Department of Public Health \& Community Medicine, Faculty of Medicine, Tanta University \\ *Corresponding author: y.hassan@psau.edu.sa
}

\begin{abstract}
Introduction: Childhood obesity is a serious non-communicable public health problem with negative physical, social, and mental health consequences. Factors contributing to childhood obesity are school nutrition, excessive snacks, fast food, lack of physical activity and family behavior. Increasing rates of overweight and obesity in children \& adolescents in Egypt signal a very alarming trend indicating an urgent need for development of strategies to address this new problem. Aim of the Study to determine the prevalence of overweight and obesity among primary school children in Minia Governorate, Egypt and identify some socio-demographic, dietary and behavioral factors that govern the problem of obesity. Subjects and Methods: This is a cross sectional study carried out at public primary schools during the academic year 2014-2015. Cluster sampling technique was used. Students aged 6-12 years old with a total number of 250 students of both sexes were included in the study. Data were collected from the parents of all children through questionnaire including Socio demographic data, life style habits and dietary habits. Results: The prevalence of overweight and obesity is relatively high (58.6\%) distributed as $34.2 \%$ overweight and $(24.4 \%)$ obese. Obesity is more prevalent among $(8<10$ years) age group, female, rural resident students. More than half of the obese children belong to university educated fathers (54.9\%) and mothers (58.2\%). Of obese and overweight children, 75.4\%belong to professional employee and clerical fathers. Skipping breakfast, regular intake of carbohydrates, dairy, fat and sweat meals were positively significantly associated with obesity, meanwhile high rate of active play (7 times or more per week), low rate of screen time (2 hours or less per day), spending holiday out door and regular intake of fruits and vegetables were negatively significantly associated with obesity. Conclusion and recommendations: This study provides further evidence of the increasingly high burden of overweight and obesity among primary school children living in Egypt. Different strategies can be implemented through many approaches to outline some important targets for anticipatory guidance to prevent obesity.
\end{abstract}

Keywords: obesity, children, socio demographic, Egypt, behavioral

Cite This Article: Yosria EL-Sayed Hossein, and Nabil Mostafa Almarhomy, "Prevalence of Social Dietary and Behavioral Risk Factors of Obesity among Primary School Children in Minia Governorate, Egypt." American Journal of Nursing Research, vol. 5, no. 2 (2017): 53-62. doi: 10.12691/ajnr-5-2-3.

\section{Introduction}

Prevalence of childhood obesity is rising around the world. The World Health Organization (WHO) has addressed obesity as a global epidemic. There are 155 million (1 in 10) children classified as overweight, and around 30-45 million as obese, worldwide [1]. According to WHO, non-communicable diseases will account for approximately three quarters of all deaths in developing world by the year 2020. The increase in obesity may be particularly rapid in developing countries [2]. The importance of obesity and overweight among children has been highlighted as obesity incidence among adolescents (10 to 18 years) in Egypt is rising rapidly, being reported that overweight represent $11.5 \%$ in boys and $15.2 \%$ in girls, while obese adolescents are $6.5 \%$ in boys and $7.7 \%$ in girls [3].

Childhood obesity is currently a major health problem in many countries of the world. Over the last few decades, an epidemic of childhood overweight and obesity occurred worldwide [4]. Overweight affects both the children health and their social integration and these children tend to become obese adults [5]. Children and youth obesity refers to the age and gender specific body mass index BMI scores that are equal to or greater than the 95 the percentile as indicated on BMI charts. A child is considered obese if his/ her BMI exceeds the cut off point for his or her age. Overweight is defined as BMI of 25 to 29.9 [6]. The prevalence of overweight and obesity varies quite considerably in different parts of the world. In Spain, the prevalence of overweight in students aged 6-16 years was $40 \%[7,8,9]$. In the USA the prevalence of overweight 
and obesity among children has been reported to be $22 \%$ and 11\%respectively [10]. Some Middle East and Asian countries have documented a significant increasing rate in the past decade. In Qatar the prevalence of overweight in boys was $28.6 \%$ and in girls was $18.9 \%$ [11], while in Kuwait it was $30 \%$ in boys and $31.8 \%$ in girls [12].

In a report from the Egyptian national nutrition institute there is increasing prevalence of obesity among children and adolescents reaching 5.8\% among males and 9.7\% among females [13]. Also in another report it is mentioned that overweight and obesity affected $1.6 \%$ of 2-6 years old, $4.9 \%$ of $6-10$ years old,14.7\% of $10-14$ years old and $13.4 \%$ of $14-18 y e a r s$ old children [8].

Prevalence of obesity not only increases with age, but there is greater likelihood that obesity beginning at early childhood will persist throughout the life span. Dramatic increase in prevalence of childhood overweight/obesity and its resultant co-morbidities such as, heart disease, hypertension, type II diabetes mellitus and early atherosclerosis warrants strong and comprehensive efforts at the preventive level [15].

There are different factors contributing to childhood obesity, such as, schools nutrition, excessive snacks, fast food, lack of physical activity, family behavior, economic and social, and media technologies such as television, internetlcomputer, and wide spread of video games technology, which negatively affect childhood obesity [16]. Also Fahmi S. and EL- Sherbini A [17] reported that, school teachers play an important role in combating childhood obesity and implementing preventative strategies as children tend to get habits about how they eat when they are young. Combating childhood obesity is considered globallyas a health priority.

Early prevention with appropriate interventions is particularly valuable for children at risk. It is here that the potential role of the educational institutions stands undisputed. Schools are probably the ideal medium to acquire knowledge and skills combined with an environment that makes healthy choices possible throughout their lives.

The rapid rise in the rates of overweight and obesity in recent years cannot be attributed to genetic factors. The genetic characteristics of the human population have not changed in the last three decades, but the prevalence of overweight has tripled among school age children during this time [18].

Changing dietary patterns, community design and infrastructure characteristics, sedentary lifestyle and a decline in physical activity are believed to contribute to the world wide obesity epidemic among both adults and children [18].

Dramatic increase in obesity has resulted in a rush to develop and disseminate obesity prevention programs based on theories of behavior change. Identification modifiable risk factors of childhood overweight, may be an important targets.

BMI at age 7 or 8 is a good predicator of obesity. This could provide a useful tool to help in prevention of obesity because it would identify children at risk before the development of obesity which may be more successful and beneficial than treatment of established sever obesity in adolescence or adulthood $[19,20]$.

\section{Am of the Work}

1. Determine the prevalence of overweight and obesity among primary school children in Minia Governorate.

2. Identify some socio- demographic, dietary and behavioral factors that govern the problem of obesity among primary school children.

\section{Subjects and Methods}

\subsection{Design}

This is a cross sectional study.

A) Setting

The study was carried out in primary public schools at Magagah district, Minia governorate, Egypt, during the academic year 2015-2016. Fourteen primary public schools (3 urban and 11 rural school) belong to this district.

B) Sample size

The sample size was calculated to be 200. Data were collected from 250 child.

C) Sampling Technique

Using cluster sampling technique, the students of the study were collected from randomly selected schools (one urban and two rural) district. And take sample of the student of each class in different educational grade within each selected school.

\section{D) Subjects}

A total number of 250 students aged 6-12 years old of both sexes was included in the study.

- Inclusion Criteria

Male and female healthy children aged 6-12 years old, from Magaggh district-Minia governorate.

- Exclusion Criteria

Children younger than 6 years old or older than 12 years old, and those with causes of secondary obesity as endocrinal disorders, genetic syndromes, and CNS disorders.

E) Study Tools and Methods

All students were subjected to the following:

- Students were weighed to the nearest one kg, lightly dressed and barefooted.

- Standing height was measured to the nearest one cm, with shoes off, feet together and head in the Frankfort horizontal plane [15].

- The body mass index (BMI) was calculated from a person's weight in kilograms and height in meters $\left(\mathrm{kg} / \mathrm{m}^{2}\right)$.

- The reliability of measurements of height and weight were assessed by repeated measurement on the same student with an intra class correlation coefficient of $>0.95$.

- BMI was tabulated according to percentile weight/age and height/age, according to WHO table, 2008.

F) The international age - and gender- specific child BMI cut off - points were used to define over weight and obesity [16].

1- BMI $<25.0 \mathrm{~kg} / \mathrm{m}^{2}$ were classified as normal weight and underweight. 
2- BMI 25.0 - $29.9 \mathrm{~kg} / \mathrm{m}^{2}$ over weight.

3- BMI $\geq 30.0 \mathrm{Kg} / \mathrm{m}^{2}$ obesity.

Data were collected from the parents of all children through a well-designed pre tested validated structured questionnaire (self-administered). The questionnaire was designed including four different parts:

\section{The socio-demographic data regarding:}

- The age, sex, residence, family pattern, number of family members, number of rooms, father's education, father's occupation, mother's education and mother's occupation.

Social score was calculated and divided to: High, Middle and social standard, guided by 3 parameters; education and work of the mother, education of the father and crowding index (number of family members divided by the number of rooms) with total score 25.

- High social class = Scores from 19-25

- Middle social class= Scores from12-18

- Low social class= Scores from 6-11.

\section{The life style habits were considered regarding:}

- Presence of active play (player exercise enough to sweat and /or breath hard), its frequency per week.

- Screen time (number of daily hours watching TV or computer)

- Spending leisure time at home.

3. Dietary habits were considered regarding: regular consumption of breakfast and supper, intake and frequency of snacks, and intake of the five food groups (cereals-fruits and vegetables-meats-dairy products-fat and sweets) through last week.

4. Selective food frequency questionnaire: Subjects were asked to indicate how often on average they consumed energy-dense foods (carbohydrate and fat rich foods) over an extended period of time (8).

\subsection{Statistical Design}

Statistical analysis of the data including data coding, entry, sorting and statistical manipulations were performed. The collected data were tabulated and analyzed statistically using SPSS program version 16. The accepted level of significance in this study was $0.05(\mathrm{P}<0.05)$.

\subsection{Ethical Consideration}

- An official permission was obtained from the ministry of Education. Communication with the administrators of schools was done to ensure maximum cooperation.

- A written consent from each student parents with an explanation of the purpose of the study and ensuring privacy was considered.

\section{Results}

Table 1 shows that the prevalence of overweight and obesity was lowest (53.11\%) in age group $6 \longrightarrow 8$ years, whereas the highest prevalence was revealed in $8-<10$ years age group (60.7\%). It illustrates that the prevalence of overweight and obesity was higher among girls (70.6\%), rural residents $(60.8 \%)$ and students with one parent family (78.3\%). The majority of low social class children were overweight (75\%). Although there were differences between the different groups regarding different socio demographic aspects yet they are only significant regarding residence, family pattern and social class.

Table 2 shows that more than half of obese children belonged to university educated fathers (54.1\%) and mothers (57.4\%) while most of the normal weight children belonged to pre university educated fathers (60\%) and mothers (70\%) (Secondary- preparatory- primary read and write\& illiterate). The difference statistically significant regarding mother education and father education also it shows that $75.4 \%$ of obese and most of overweight children (80.7\%) belonged to professional, employee and clerical fathers and about (62\%) of normal weight children belonged to non working mothers. The differences are statistically significant regarding father occupation and mother occupation.

Table 1. Distribution of the studied groups according to some socio demographic characters

\begin{tabular}{|c|c|c|c|c|c|c|c|c|c|}
\hline BMI Classification & \multicolumn{2}{|c|}{$\begin{array}{c}\text { Normal weight } \\
(n=100)\end{array}$} & \multicolumn{2}{|c|}{ Overweight (n=85) } & \multicolumn{2}{|c|}{ Obese $(n=61)$} & \multicolumn{2}{|c|}{$\begin{array}{c}\text { Under weight } \\
(n=4)\end{array}$} & P. Value \\
\hline \multicolumn{10}{|l|}{ Age ( years) } \\
\hline 6 6—8 $\quad(\mathrm{n}=85)$ & 36 & 42.4 & 26 & 30.6 & 20 & 23.5 & 3 & 3.5 & \multirow[b]{3}{*}{$\mathrm{P}>0.05$} \\
\hline $8-<10(n=84)$ & 33 & 39.3 & 31 & 36.9 & 20 & 23.8 & 0 & 0 & \\
\hline $10-12(n=81)$ & 31 & 38.3 & 28 & 34.6 & 21 & 25.9 & 1 & 1.2 & \\
\hline \multicolumn{10}{|l|}{ Sex } \\
\hline Male (n =123) & 51 & 41.5 & 40 & 32.5 & 29 & 23.6 & 3 & 2.4 & \multirow[b]{2}{*}{$\mathrm{P}>0.05$} \\
\hline Female (n =127) & 49 & 38.6 & 45 & 35.4 & 32 & 25.2 & 1 & 0.8 & \\
\hline \multicolumn{10}{|l|}{ Residence } \\
\hline Urban (n =125) & 53 & 42.4 & 48 & 38.4 & 22 & 17.6 & 2 & 1.6 & \multirow[b]{2}{*}{$\mathrm{P}<0.05$} \\
\hline Rural (n =125) & 47 & 37.6 & 37 & 29.6 & 39 & 31.2 & 2 & 1.6 & \\
\hline \multicolumn{10}{|l|}{ Familypattern } \\
\hline One parent $(n=23)$ & 4 & 17.4 & 10 & 43.5 & 8 & 34.8 & 1 & 4.3 & \multirow[b]{2}{*}{$\mathrm{P}<0.05$} \\
\hline Both parents (n=227) & 96 & 42.3 & 75 & 33.1 & 53 & 23.3 & 3 & 1.3 & \\
\hline \multicolumn{10}{|l|}{ Socialclass } \\
\hline High social class $(\mathrm{n}=172)$ & 72 & 41.8 & 54 & 31.3 & 45 & 26.0 & 1 & 0.9 & \multirow{3}{*}{$\mathrm{P}<0.05$} \\
\hline Middle social class $(n=66)$ & 26 & 39.4 & 22 & 33.3 & 16 & 24.3 & 2 & 3.0 & \\
\hline Low social class $(n=12)$ & 2 & 16.7 & 9 & 75.0 & 0 & 0.0 & 1 & 8.3 & \\
\hline Total & 100 & 40.0 & 85 & 34 & 61 & 24.4 & 4 & 1.6 & \\
\hline
\end{tabular}


Table 2. Distribution of the studied group according to their parent's education and occupation

\begin{tabular}{|c|c|c|c|c|c|c|c|c|c|c|}
\hline \multirow[b]{2}{*}{ Variable } & \multirow[t]{2}{*}{ Groups } & \multicolumn{2}{|c|}{ normal weight } & \multicolumn{2}{|c|}{ Over- weight } & \multicolumn{2}{|c|}{ Obese } & \multicolumn{2}{|c|}{ Under weight } & \multirow{2}{*}{ P.value* } \\
\hline & & No & $\%$ & No & $\%$ & No & $\%$ & No & $\%$ & \\
\hline \multicolumn{11}{|c|}{ Fathers 'education } \\
\hline Illiterate & & 10 & 10.0 & 5 & 5.9 & 2 & 3.3 & 1 & 25.00 & \multirow{6}{*}{$\mathrm{P}<0.05$} \\
\hline read\& write & & 17 & 17.0 & 13 & 15.3 & 5 & 8.2 & 1 & 25.0 & \\
\hline Primary & & 4 & 4.0 & 3 & 3.5 & 2 & 3.3 & 1 & 25.0 & \\
\hline Preparatory & & 10 & 10.0 & 3 & 3.5 & 3 & 4.9 & 1 & 25.0 & \\
\hline Secondary & & 19 & 19.0 & 21 & 24.7 & 16 & 26.2 & 0 & 0 & \\
\hline University & & 40 & 40.0 & 40 & 47.1 & 33 & 54.1 & 0 & 0 & \\
\hline \multicolumn{11}{|c|}{ Fathers 'occupation } \\
\hline Not work & & 2 & 2.0 & 0 & 0.0 & 0 & 0.0 & 0 & 0.0 & \multirow{5}{*}{$\mathrm{P}<0.05$} \\
\hline unskilled worker & & 18 & 18.0 & 5 & 5.9 & 3 & 4.9 & 1 & 25.0 & \\
\hline skilled worker & & 27 & 27.0 & 11 & 13.0 & 12 & 19.7 & 0 & 0.0 & \\
\hline employee/clerical & & 40 & 40.0 & 45 & 53.0 & 35 & 57.4 & 2 & 50.0 & \\
\hline Professional & & 13 & 13.0 & 24 & 28.1 & 11 & 18.0 & 1 & 25.0 & \\
\hline \multicolumn{11}{|c|}{ Mothers 'education } \\
\hline Illiterate & & 28 & 28.0 & 4 & 4.7 & 2 & 3.3 & 0 & 0.0 & \multirow{6}{*}{$\mathrm{P}<0.05$} \\
\hline read\&write & & 8 & 8.0 & 8 & 9.4 & 2 & 3.3 & 0 & 0.0 & \\
\hline Primary & & 7 & 7.0 & 2 & 2.4 & 3 & 4.9 & 1 & 25.0 & \\
\hline Preparatory & & 5 & 5.0 & 5 & 5.9 & 4 & 6.6 & 2 & 50.0 & \\
\hline Secondary & & 22 & 22.0 & 21 & 24.7 & 15 & 24.5 & 0 & 0.0 & \\
\hline University & & 30 & 30.0 & 45 & 52.9 & 35 & 57.4 & 1 & 25.0 & \\
\hline \multicolumn{11}{|c|}{ Mothers occupation } \\
\hline not work & & 62 & 62.0 & 15 & 17.6 & 20 & 32.8 & 2 & 50.0 & \multirow{5}{*}{$\mathrm{P}<0.05$} \\
\hline unskilled worker & & 15 & 15.0 & 9 & 10.6 & 6 & 9.8 & 1 & 25.0 & \\
\hline Skilled worker & & 10 & 10.0 & 17 & 20.0 & 16 & 26.2 & 0 & 0.0 & \\
\hline employee/clerical & & 4 & 4.0 & 38 & 44.7 & 7 & 11.5 & 1 & 25.0 & \\
\hline professional & & 9 & 9.0 & 6 & 7.1 & 12 & 19.7 & 0 & 0.0 & \\
\hline Total & & 100 & & 85 & & 61 & & 4 & & \\
\hline
\end{tabular}

Table 3. Distribution of the studied group according to some patterns of daily behavioral activities

\begin{tabular}{|c|c|c|c|c|c|c|}
\hline \multirow[b]{2}{*}{ Physical activity } & \multirow{2}{*}{ The studied group } & \multicolumn{2}{|c|}{ None obese*** } & \multicolumn{2}{|c|}{ Obese** } & \multirow{2}{*}{ P. value } \\
\hline & & No. & $\%$ & No. & $\%$ & \\
\hline \multicolumn{7}{|c|}{ Rate of Active play/week } \\
\hline Never & $(\mathrm{n}=24)$ & 7 & 6.8 & 17 & 11.6 & \multirow{4}{*}{$\mathrm{P}<0.05$} \\
\hline less than 7times & $(n=94)$ & 15 & 14.6 & 79 & 53.7 & \\
\hline 7 times & $(\mathrm{n}=125)$ & 75 & 72.8 & 50 & 34 & \\
\hline more than 7times & $(n=7)$ & 6 & 5.8 & 1 & 0.7 & \\
\hline \multicolumn{7}{|c|}{ Screen time (NO. Hours TV or Computer per day) } \\
\hline $1 \mathrm{hr}$. & $(\mathrm{n}=18)$ & 13 & 12.7 & 5 & 3.4 & \multirow{4}{*}{$\mathrm{P}<0.05$} \\
\hline $2 \mathrm{hrs}$ & $(\mathrm{n}=143)$ & 71 & 68.9 & 72 & 49 & \\
\hline 3hrs & $(\mathrm{n}=18)$ & 2 & 1.9 & 16 & 10.9 & \\
\hline 4 or more hrs. & $(\mathrm{n}=71)$ & 17 & 16.5 & 54 & 36.7 & \\
\hline \multicolumn{7}{|c|}{ Spending holiday At home } \\
\hline Yes & $(\mathrm{n}=84)$ & 5 & 4.9 & 79 & 53.7 & \multirow{3}{*}{$\mathrm{P}<0.05$} \\
\hline No & $(\mathrm{n}=18)$ & 12 & 11.6 & 6 & 4.1 & \\
\hline Sometimes & $(\mathrm{n}=148)$ & 86 & 83.5 & 62 & 42.2 & \\
\hline Total & & 103 & 100.0 & 147 & 100.0 & \\
\hline
\end{tabular}

*Obese $\quad=$ (obese + overweight $)$

$* * *$ Non obese $=($ normal + underweight $)$.

Table 3 shows that more than $3 / 4$ (78.6\%) of none obese had high rate of active play (7 times or more / week) while nearly $2 / 3(65.3 \%)$ of obese had low rate of active play (less than 7 times or never /week). The majority (68.9\%) of none obese students spent 2 hours per day in watching TV or using computer while more than $3 / 4$ of students spent 4 or more hours (36.7\%) are obese. More than half(53.7\%)of obese group spent holiday in the home.

High rate of active play (7 times or more per week) low screen time (2 hours or less per day) and spending holiday outside home were negatively associated with obesity with statistically significant results. 
Table 4 illustrates that more than half of non obese children had breakfast regularly (51\%), most of obese children regularly had supper (61\%) and most of children (60.4\%) had foods or drinks between the main meals were obese.

Table 4 also shows that the majority of children either obese or non obese during the last weak regularly consumed carbohydrates and dairy meals and occasionally consume protein, fat and sweat meals. $24 \%$ of non obese children regularly consume fruit and vegetable meals.

Skipping the breakfast meal, regular intake of supper, intake of carbohydrates meals, dairy meals, fat and sweet meals were positively associated with obesity while regular intake of fruits and vegetables was negatively associated with obesity with statistically significant results.

Table 4. Distribution of the studied group according to some dietary habits

\begin{tabular}{|c|c|c|c|c|c|c|}
\hline \multirow{2}{*}{ Dietary habits } & \multirow[t]{2}{*}{ Studied group } & \multicolumn{2}{|c|}{$\begin{array}{c}\text { None obese } \\
(n=104)\end{array}$} & \multicolumn{2}{|c|}{ Obese $(n=146)$} & \multirow[t]{2}{*}{ P.value } \\
\hline & & No. & $\%$ & No. & $\%$ & \\
\hline \multirow{3}{*}{ Intake of breakfast at home } & Often & 53 & 51 & 41 & 28.1 & \multirow{3}{*}{$<0.05$} \\
\hline & Occasional & 18 & 17.3 & 30 & 20.5 & \\
\hline & Never & 33 & 31.7 & 75 & 51.4 & \\
\hline \multirow{3}{*}{ Intake of supper } & Often & 36 & 34.6 & 89 & 61 & \multirow{3}{*}{$<0.05$} \\
\hline & Occasional & 56 & 53.8 & 52 & 35.6 & \\
\hline & Never & 12 & 11.6 & 5 & 3.4 & \\
\hline \multirow{2}{*}{ Intake of food or drink between main meals } & Yes & 82 & 78.9 & 125 & 85.6 & \multirow{2}{*}{$>0.05$} \\
\hline & No & 22 & 21.1 & 21 & 14.4 & \\
\hline \multicolumn{7}{|l|}{ Last weekMeals } \\
\hline \multirow{2}{*}{ Intake of Carbohydrates meals } & everyday & 87 & 83.7 & 109 & 74.4 & \multirow{2}{*}{$<0.05$} \\
\hline & Occasional & 17 & 16.3 & 37 & 25.3 & \\
\hline \multirow{3}{*}{ Intake of ProteinMeals } & everyday & 7 & 6.7 & 11 & 7.5 & \multirow{3}{*}{$>0.05$} \\
\hline & Occasional & 91 & 87.5 & 129 & 88.4 & \\
\hline & Never & 6 & 5.8 & 6 & 4.1 & \\
\hline \multirow{2}{*}{ Intake of Dairy Meals } & everyday & 93 & 89.4 & 139 & 95.2 & \multirow{2}{*}{$<0.05$} \\
\hline & Occasional & 11 & 10.6 & 7 & 4.8 & \\
\hline \multirow{3}{*}{$\begin{array}{l}\text { Intake of Fat and Sweet } \\
\text { Meals }\end{array}$} & everyday & 5 & 4.8 & 66 & 45.2 & \multirow{3}{*}{$<0.05$} \\
\hline & Occasional & 98 & 94.2 & 80 & 54.8 & \\
\hline & Never & 1 & 1 & 0 & 0 & \\
\hline \multirow{2}{*}{ Intake of Fruit and Vegetable Meals } & everyday & 79 & 76 & 46 & 31.5 & \multirow{2}{*}{$<0.05$} \\
\hline & Occasional & 25 & 24 & 100 & 68.5 & \\
\hline \multicolumn{2}{|l|}{ Total } & 104 & 100 & 146 & 100 & \\
\hline
\end{tabular}

Table 5. Distribution of the students according to frequency of consumption of carbohydrate-rich foods

\begin{tabular}{|c|c|c|c|c|c|c|}
\hline \multirow{2}{*}{\multicolumn{2}{|c|}{ Studied group carbohydrate-rich foods. }} & \multicolumn{2}{|c|}{ None obese*** $(\mathrm{n}=104)$} & \multicolumn{2}{|c|}{ Obese** $^{* *}(\mathrm{n}=146)$} & \multirow{2}{*}{ P value* } \\
\hline & & No. & $\%$ & No. & $\%$ & \\
\hline \multirow{3}{*}{ Bread } & $\geq 2 / \mathrm{d}$ & 93 & $\begin{array}{l}89.4 \\
\end{array}$ & 122 & 83.6 & \multirow{3}{*}{$<0.05$} \\
\hline & $1 / \mathrm{d}$ & 11 & 10.6 & 18 & 12.3 & \\
\hline & 5-6/wk. & 0 & 0 & 6 & 4.1 & \\
\hline \multirow{3}{*}{ Rice and Macaroni } & $\geq 2 / \mathrm{d}$ & 8 & 7.7 & 32 & 21.9 & \multirow{3}{*}{$<0.05$} \\
\hline & $1 / \mathrm{d}$ & 47 & 45.2 & 78 & 53.4 & \\
\hline & $\geq 1 /$ wk. & 49 & 47.1 & 36 & 24.7 & \\
\hline \multirow{3}{*}{ Soft Drinks } & $\geq 1 / \mathrm{d}$ & 8 & 7.7 & 16 & 10.9 & \multirow{3}{*}{$>0.05$} \\
\hline & $>1 /$ wk. & 29 & 27.9 & 36 & 24.7 & \\
\hline & $\leq \mathbf{1} / \mathbf{w k}$. & 67 & 64.4 & 94 & 64.4 & \\
\hline \multirow{4}{*}{ Chocolate } & $\geq 1 / \mathrm{d}$ & 6 & 5.7 & 23 & 15.8 & \multirow{4}{*}{$<0.05$} \\
\hline & $\geq 1 /$ wk. & 56 & 53.8 & 82 & 56.2 & \\
\hline & $<\mathbf{1} /$ wk. & 41 & 39.5 & 36 & 24.6 & \\
\hline & 1-3month & 1 & 1 & 5 & 3.4 & \\
\hline \multirow{2}{*}{ Cakes and Biscuits } & $\geq 1 / d$ & 18 & 17.3 & 71 & 48.6 & \multirow{2}{*}{$<0.05$} \\
\hline & $\geq 1 /$ wk. & 86 & 82.7 & 75 & 51.4 & \\
\hline \multirow{3}{*}{ Jam and Honey } & $\geq 1 / \mathrm{d}$ & 15 & 14.4 & 32 & 21.9 & \multirow{3}{*}{$<0.05$} \\
\hline & $\geq 1 /$ wk. & 81 & 77.9 & 104 & 71.2 & \\
\hline & 1-3month & 8 & 7.7 & 10 & 6.9 & \\
\hline \multirow{3}{*}{ Halawa\&Tehina } & $\geq 1 / d$ & 27 & 26 & 31 & 21.2 & \multirow{3}{*}{$<0.05$} \\
\hline & $\geq 1 /$ wk. & 76 & 73 & 114 & 78.1 & \\
\hline & 1-3month & 1 & 1 & 1 & 0.7 & \\
\hline
\end{tabular}

$* *$ Obese $=$ (obese + overweight $)$

$* * *$ Non obese $=($ normal + underweight $)$. 
Table 6. Distribution of the students according to the frequency of consumption of fat-rich foods

\begin{tabular}{|c|c|c|c|c|c|c|}
\hline \multicolumn{2}{|l|}{ The studied group } & \multicolumn{2}{|c|}{ None obese*** } & \multicolumn{2}{|c|}{ Obese** } & \multirow[b]{2}{*}{ P value* } \\
\hline fat-rich foods & Frequency & NO. & $\%$ & NO. & $\%$ & \\
\hline \multirow{3}{*}{ Ice cream } & $\geq \mathbf{1 / d}$ & 10 & 9.6 & 13 & 8.9 & \multirow{3}{*}{$\mathrm{P}>0.05$} \\
\hline & $>1 /$ wk. & 74 & 71.2 & 115 & 78.8 & \\
\hline & $<\mathbf{1} /$ wk. & 20 & 19.2 & 18 & 12.3 & \\
\hline \multirow{3}{*}{$\begin{array}{l}\text { full cream milk products } \\
\text { \&High Fat cheese }\end{array}$} & $\geq 2 / \mathrm{d}$ & 13 & 12.5 & 40 & 27.4 & \multirow{3}{*}{$\mathrm{P}<0.05$} \\
\hline & $1 / \mathrm{d}$ & 47 & 45.2 & 50 & 34.2 & \\
\hline & $>1 /$ wk. & 44 & 42.3 & 56 & 38.4 & \\
\hline \multirow{3}{*}{ Butter, Cream\& Mayonnaise } & $\geq 1 / \mathrm{d}$ & 1 & 1 & 22 & 15.1 & \multirow{3}{*}{$\mathrm{P}<0.05$} \\
\hline & $\geq 1 /$ wk. & 30 & 28.8 & 90 & 61.6 & \\
\hline & 1-3 months & 73 & 70.2 & 34 & 23.3 & \\
\hline \multirow{3}{*}{ Deep fried foods } & $\geq 1 / d$ & 26 & 25 & 33 & 22.6 & \multirow{3}{*}{$\mathrm{P}<0.05$} \\
\hline & $\geq 1 /$ wk. & 72 & 69.2 & 107 & 73.3 & \\
\hline & 1-3/mo. & 6 & 5.8 & 6 & 4.1 & \\
\hline \multirow{3}{*}{ Pizza } & $\geq 1 /$ wk. & 32 & 30.8 & 68 & 46.6 & \multirow{3}{*}{$\mathrm{P}<0.05$} \\
\hline & $<\mathbf{1} /$ wk. & 33 & 31.7 & 44 & 30.11 & \\
\hline & Never & 39 & 37.5 & 34 & 23.3 & \\
\hline \multirow{3}{*}{ Processed Meats } & $\geq 1 / d$ & 10 & 9.6 & 19 & 13 & \multirow{3}{*}{$\mathrm{P}>0.05$} \\
\hline & $>1 /$ wk. & 15 & 14.4 & 15 & 10.3 & \\
\hline & $<\mathbf{1} /$ wk. & 79 & 76 & 112 & 76.7 & \\
\hline \multirow{3}{*}{ Chips and fried Snakes } & $\geq 2 / \mathrm{d}$ & 12 & 11.5 & 28 & 19.2 & \multirow{3}{*}{$\mathrm{P}<0.05$} \\
\hline & $1 / \mathrm{d}$ & 8 & 7.7 & 27 & 18.5 & \\
\hline & $\geq 1 /$ wk. & 84 & 80.8 & 91 & 62.3 & \\
\hline
\end{tabular}

** Obese $=$ (obese + overweight $)$

$* * *$ Non obese $=($ normal + underweight $)$.

Table 5 shows that the majority of both groups consume bread twice or more per day, soft drinks one time or less per week, chocolate, cakes and biscuits Jam and Honey, Halawa and Tehina one or more per week. Also it shows that more than half of obese children consume rice and macaroni once per day. This table also illustrates that eating bread, rice and macaroni, chocolate, cakes and Biscuits, Jam and Honey and Halawa Tehina is significantly higher for the obese than the non obese children.

Table 6 shows that the majority of both groups consumed ice-cream, deep- fried foods, chips and fried snakes once or more per week. Most of obese students consumed(full cream milk products\& high fat cheese), (butter, cream and mayonnaise) and(chips and fired snakes) once or more per week. Also it shows that consumption of full cream milk products and higher fat cheese, butter, cream, Deep Fried foods, Pizza and chips and fried snacks were statistically significantly associated with obesity.

\section{Discussion}

Obesity in childhood and adolescence has adverse consequences on premature mortality and physical morbidity in adulthood and is associated with impaired health during childhood itself. Once obesity is established in children it is hard to reverse. Monitoring the prevalence of obesity in order to plan services for the provision of care and to access the impact of policy initiatives is essential [20].

This study revealed that the overall prevalence of obesity was $58.4 \%$ distributed as $34 \%$ overweight and $24.4 \%$ obese. The high prevalence shows Egypt is in a state of increasing childhood overweight.
These results agree with Ezzat, et al., (2011) [21] who found that among primary school, in Alexandria Governorate, Egypt, the prevalence of obesity was $57.8 \%$ distributed as $37.4 \%$ overweight and $20.4 \%$ obese.

On the contrary a study conducted in Damanhur city in El- Behera Governorate, Egypt( 2006), revealed that the overall prevalence of overweight was $17.2 \%$ and that of obesity was $19.8 \%$ with a total of $37 \%$ [19]. This difference in rates may reflect the steady rapid increase of the prevalence of obesity due to the rapid social changes in the Egyptian community.

The prevalence of obesity and overweight in other parts of the worlds varies quite considerably. The present study reported higher figures than others. In Greek, the prevalence of overweight among children aged 6-10 years was $25.3 \%$ [22].

In Malaysia, the prevalence of overweight and obesity among children aged 9-10 years was $16.3 \%$ and $6.3 \%$ respectively [23], in India, the prevalence of overweight was reported as $10 \%$ among $10-15$ years old [24] and in Costarica, the prevalence of overweight and obesity among children aged 7-12 years was 34.5\% and 26.2\% respectively [25].

Other studies reported higher rates than ours. For example, in study done by Manzoli et al in 2005 in Italy, the prevalence of overweight in students aged 6-16 years was 40.6\% [26] and in Spain it was40.0\% [4].

The differences may be attributed partially to the effect of genetic, lifestyle and environmental factors and variations in the age groups of the samples and because of different study methods and definitions of obesity and underweight across the various studies [27].

In this study the prevalence rate of overweight and obesity is higher among female subjects. These results agree with Gebre michael and Chere in Addis Ababa, who 
found that sex specific prevalence of overweight and obesity shows $7.7 \%$ and $3.2 \%$ of male participants were obese. For females these rates $12 \%$ and $2.5 \%$ for overweight and obese respectively [55]. The finding of this study is also consistent with that done in Douala, Cameronin2010, where the prevalence of overweight ranged from $6.4 \%$ to $8.2 \%$ in boys and from $10.7 \%$ to $17.2 \%$ in girls, whereas prevalence of obesity ranged from $1.4 \%$ to $5.5 \%$ in boys and from 2.4 to $8.6 \%$ in girls. This may be explained by our society culture in which females spent most of their time at home.

These results also agreed with Tabatabaei et al [28]. In the contrary, they don't agree with other studies. Krasass et al 2004 found the prevalence of obesity was significantly higher in males than females [29], as did Langendijk et al 2003, in Northern Thailand among children aged 7-9 years [30].

Prevalence of underweight according to WHO 2007 reference was higher in boys as compared to girls, 9.2\% and 5.5\% respectively [20]. The sex specific prevalence of underweight was higher in our study which revealed that the prevalence of underweight in boys as compared to girls, (2.4\%)male and (0.8\%)female.

Possibly, this may be explained by the different patterns of growth weight in respect to age and sex, to the different nutritional behavior or to other life style related factors between the two sexes especially in developing countries as boys are likely to have more opportunities for exercise playing and recreation, whereas girls may suffer from restrictions of social mobility as they grow older [11]. The difference might also in part be explained by different study methods and definition of obesity and underweight across various studies [27].

One key characteristic of the family that is associated with childhood obesity is family structure. Researches find that children who live in two- parent families are less likely to be obese than children who live in single parent family [31].

The results of the current study agree with this. It revealed that the majority of the students with one parent are overweight and obese (43.5\%) and (34.8\%) respectively. Also this could be attributed to the more social and psychological adjustment of the both parent families which is reflected on the healthy dietary habits compared with single parent families.

The current study revealed that there are changes in the pattern of the $50^{\text {th }}$ percentile of BMI charts regarding the different age groups. This may reflect and could be explained by the changes in growth rates and growth spurt among different age groups. These results were also confirmed by others [21,32,33].

In developing countries, the transition from rural agrarian to urban economies has accelerated the appearance of obesity, and is accompanied by shift in overall health burden from infectious disease and under nutrition to chronic diseases such as cardiovascular disease, cancer and diabetes [34].

This is evident in this study which showed that the majority of the obese students reside in rural areas which can be explained by the increased urbanized influences on rural areas due to improved accessibility to urban adjacent. But this is not in agreement who found that obesity was less prevalent in rural students which may be contributed to the fact that rural life style and dietary habits there may be adjusted factors of weight among rural residents [19].

Socioeconomic status seems to be a factor in obesity. Some socioeconomic factors influence quality and quantity of consumed food through varied income and food habits [36].

The current work revealed that regarding the social class it was found that the majority of low social class children were overweight (75\%) with statistically significant differences regarding social class among different groups.

This doesn't agree with Fernald, et al. and others $[37,38,39,40]$ who mentioned that body mass index was significantly higher in the highest social standard group. They stated that in developed countries obesity seems to be more common among poorer communities while in low income developing countries, obesity was associated with higher socioeconomic status, whereas among lower socioeconomic status, under nutrition was more likely to be a problem.

This can partly be explained by the fact that both the rich and poor can afford energy-rich food. The rich can buy expensive foods with higher energy content while the poorer consume foods with high starch content to provide a cheap, bulky and satisfying meal. The level of physical activity will be reduced in both the rich due to motorized transportation and mechanization and the poor, due to the inability to afford club membership.

Parents' level of education is one of the determinants of the prevalence of obesity. For the developing countries, the higher the level of parents' education, the higher will be the prevalence of overweight and obesity [41]. This come in accordance with the results of this study where more than half of the obese children belonged to university educated fathers (54.1\%) and mothers (57.4\%).

These results could be explained by the fact that the highly educated parents can get better chances for work and consequently a persistent source of money. The higher domiciliary income the family gains from parent's work increases their purchasing power, which may be directed mostly towards food in addition to the more sedentary style of living [42].

Parents' occupation and employee status are other social factors that were found to influence the prevalence of overweight and obesity. This study revealed that higher occupational classes were significantly associated with obesity. This could be explained by the fact that more work chances achieved by mothers raises the economic level and increases the purchasing power of the family. In addition, less time is spent indoors, the chances of consumption of healthy home-made meals will decrease in addition to the lack of attention to the children during mother's absence which increases the opportunity of intake of snacks and outdoor meals which are rich in fat and sugar [43].

As the problem of obesity continues, the child becomes more inactive and a vicious circle is formed which promotes further obesity [44]. Not only are obese children physiologically different from children of normal weight, but they also have demonstrated significant emotional differences, they tend to have a poor self-image which make them less likely to get involved in games and sports [45]. 
The effect of physical inactivity and sedentary behavior was also explored in this study. This study reported that the obese children were more likely to have low level of active play than non-obese (68.6\% and $21.2 \%$ respectively) and obese children were reported to have high screen time than non-obese (47.5\% and $18.3 \%$ respectively). These results are in agreement with Anderson et al., [18]. Spending too much time watching T.V might increase the risk for developing obesity, but obese children might also increase the time watching T.V.as a consequence of their weight status, thus the time children spent watching T.V. might displaces time spent in physical activity [1]. This may give more chance to promote intake of unhealthy foods while watching T.V. [46,47,48,49].

In the contrary, other studies mentioned the fact that none of physical activity and sedentary behavior variables predicted over weight or obesity [50].

Children who don't eat breakfast, are more likely to consume unhealthy foods during the day which induces the development of overweight [51].

The current study showed that more than half of non obese children have breakfast regularly (51\%). This agrees with other studies which have shown that skipping breakfast is associated with having a higher BMI and obesity [52]. Eating more calories earlier in the day may cause satiety for longer period. The habit of eating meals outdoors and even the intake of sandwiches to school were found to increase significantly the risk of obesity [53].

Another study showed that eating breakfast regularly was found to be protective for overweight. When binary logistic regression was done eating breakfast regularly has significant association [54].

It is well-known that snacking between meals lead to weight gain, particularly if what is eaten is unhealthy snacks, energy-dense, nutrient-poor food products such as sweets and beverages which are high in sugar, carbohydrates and fat $[46,47]$.

The current study showed that intake of food or drink between main meals was reported in $85.6 \%$ of obese children. This is in accordance with other studies which found that the risk of obesity was significantly higher among those who eat between meals compared to those who did not eat [54].

In the current study there were statistically significant higher differences between the obese and non obese regarding consumption of most of the selected energy dense food items. These results were in agreement with a conducted study in Damanhur city among primary school children [21].

In a study in Alexandria conducted by Tanaghoin 2004 [54] no significant differences were found between the obese and non - obese in patterns of energy - dense food items consumption.

Our study showed that the majority of both groups consume bread twice or more per day, soft drinks one time or less per week, chocolate, cakes and biscuits Jam and Honey, Halawa and Tehina one or more per week. Also it showed that more than half of obese children consume rice and macaroni once per day. It also illustrated that eating bread, rice and macaroni, chocolate, cakes and Biscuits, Jam and Honey and Halawa and Tehina was significantly higher for the obese than for the non obese children. A study conducted in Addis Ababa (2007) in primary school children showed the same results. From those food items ever bought by students, chocolate, ice cream and cake showed significant association with overweight. But in logistic regression analysis only ice-cream revealed significant association [55].

\section{Conclusion}

This study provides further evidence of the increasingly high burden of overweight and obesity among primary school children in Egypt.

The prevalence of overweight and obesity was relatively high. Obesity is more prevalent among $(8-<10$ years) age group, female, rural students. More than half of the obese children belong to university educated fathers and mothers About 3/4 of obese and overweight children belong to professional employee.

The prevalence of overweight was found to be high even comparable with the global prevalence. Among the factors identified are unhealthy dietary pattern like preferring sweet foods, eating breakfast irregularly, ice cream and frequent snacking are strongly associated with overweight.

Physical inactivity was also revealed as an important factors impacting on the risk of obesity in children. If primary preventive measures is not taken immediately, prevalence of overweight and obesity among children, might increase rapidly in the coming few years.

\section{Recommendations}

- The findings suggest a need for development of school based intervention program to increase the level of awareness of ill effects of obesity and to target all obese organic lifestyle factors during childhood and obesity related risk behavior for counseling before adverse habits are established.

- promoting active lifestyles and healthy diets should be a national public health priority. There is a need of longitudinal study to investigate the relationship between vegetable intake and overweight and/or obesity.

- Because early interventions on modifiable risk factors are likely to decrease the rate of childhood obesity, educational programs about obesity and associated health consequences should start early in childhood so as prevent the increasing prevalence of childhood obesity in Egypt.

- There must be a multispectral approach from the government, school authorities and parents to introduce polices and guidelines to help children to live healthy life like school canteen policy, healthy food practices, inclusion of health related topics in curriculum and introduction of compulsory physical training classes.

\section{References}

[1] Veldhuis L, Vogel I, Renders CM, van Rossem L, Oenema A, HiraSing RA and Raat $\mathrm{H}$. Behavioral risk factors for overweight in early childhood; the 'Be active, eat right' study. int J Behav Nutr Phys Act., 2012; Jun 15; 9: 74.

[2] Reinehr T., Schaefer A., Winkel K. and Kolip P. An effective lifestyle intervention in overweight children: Findings from a 
randomized controlled trial on 'obeldicks light", clinical nutrition 2010; 1 - 6.

[3] Knecht S., Ellger T. and Levine J. Obesity in neurobiology progress in neurobiology, 2008; 48: 85-103.

[4] Martínez Vizcaíno V1, Salcedo Aguilar F, Franquelo Gutiérrez R, Torrijos Regidor R, Morant Sánchez A, Solera Martínez M and Rodríguez Artalejo F. Prevalence of obesity and trends in cardiovascular risk factors among Spanish school children, 19922004: the Cuenca (Spain) study]. Medicina Clínica, 2006, 126: 681-685.

[5] Terrell DF. Overweight and obesity prevalence rates among youth in the Carolinas. North Carolina Medical Journal, 2002, 63: 281-286.

[6] Bener A. Prevalence of obesity, overweight, and underweight in Qatari adolescents. Food and Nutrition Bulletin, 2006, 27: 39-45.

[7] Al-Isa AN. Body mass index, overweight and obesity among Kuwaiti intermediate school adolescents age 10-14 years. European Journal of Clinical Nutrition, 2004, 58: 1273-1277.

[8] National nutrition institutes "NNI": Report on the prevalence of obesity in Egypt. 2004.

[9] Galal O.M. The nutrition transition Egypt: Obesity, Under nutrition and the food consumption context public Health nutrition, 2002, 5(1A), 141-148.

[10] Ogden C., Carroll M., Curtin L., MeDowll M., Tabak C. and Flegal Prevalence of overweight and obesity in the United States, 1999- 2004. JAMA; 2006; 295(13): 1549-1555.

[11] Ahmed J, Laghari A, Naseer M and Mehraj V. Prevalence of and factors associated with obesity a mong Pakistani schoolchildren: a school-based, cross-sectional study. East Mediterr Health J. 2013 Mar; 19(3): 242-7.

[12] Yancey AK, Fielding JE, Flores GR, Sallis JF, McCarthy WJ and Breslow L.Creating a robust public health infrastructure for physical activity promotion. Am J Prev Med. 2007; 32: 68-78.

[13] Sallis J., Patric K. and Frank E. Interventions in health care settings to promote healthful eating and physical activity in children and adolescents. Prev med 2000; 31: S112-121.

[14] Daniels SR, Arnett DK, Eckel RH, Gidding SS, Hayman LL, Kumanyika S, Robinson TN, Scott BJ, Jeor SS and Williams CL. Overweight in Children and Adolescents Pathophysiology, Consequences, Prevention, and Treatment. Circulation. 2005; 111: 1999-2012.

[15] Tokmakidis S., Christodoulos A. and Mantzouranis N. Validity of self-reported anthropometric values used to assess body mass index and estimate obesity in Greek school children. Journal of adolescent health 2007; 40: 305-310.

[16] Peltzer K and Pengpid S. Overweight and obesity and associated factors among school-aged adolescents in Ghana and Uganda. Int. J. Environ Res Public Health. 2011; Oct; 8 (10): 3859-70.

[17] Fahmi S. and EL- Sherbini A. Determining simple parameters for social classification for health research. Bulletin of H.I.P.H. 1983.

[18] Anderson, S.E, Economos, C. and Must, A. Active play and screen time in US children aged 4 to 11 years in relation to sociodemographic weight status characteristics; A Nationally representative cross- sectional analysis. BMC Public Health, 2008; Oct 22; 8: 366

[19] Mostafa A.K. The prevalence of obesity and its determinants among primary school children Damanhour city MSC thesis. High Institute of Public Health- Department of nutrition. University of Alexandria. 2006.

[20] De Onis M and Lobstein T. Defining obesity risk status in the general childhood population: Which cut-offs should we use? Int. J. Pediatr. Obes. 2010; 5:458-460.

[21] Ezzat A.M, EL Gendy M.F., Soliman D.R, Mohammed A.H. and Abou Ghazy. Body Mass Index as an Assessment Tool for Overweight and Obesity in School Children in El-Qalubia Governorate. Journal of American Science, 2011; 7(8) 240-250

[22] Krassas GE. Prevalence and trends in overweight and obesity among children and adolescents in Thessaloniki, Greece. Journal of Pediatric Endocrinology \& Metabolism, 2001, 14(Suppl. 5): 1319-1326, discussion 1365.

[23] Zaini MZ1, Lim CT, Low WY and Harun F. Factors affecting nutritional status of Malaysian primary school children.AsiaPacific Journal of Public Health, 2005, 17:71-80.

[24] Sidhu S, Marwah G and Prabhjot. Prevalence of overweight and obesity among the affluent adolescent school children of Amritsar, Punjab. Collegium Antropologicum, 2005, 29: 53-55.
[25] Núñez-Rivas HP1, Monge-Rojas R, León H and Roselló M Prevalence of overweight and obesity among Costa Rican elementary school children. Revista Panamericana de Salud Publica, 2003, 13: 24-32.

[26] Manzoli L1, Ripari P, Rotolo S, Di Giacinto G, Bellomo RG, Sorgentone S, Staniscia T, Schioppa F, Romano F and Vecchiet L. Prevalenza di obesità, sovrapeso e ipertensione nei bambini e adolescenti della provincia di Pescara [Prevalence of obesity, overweight and hypertension in children and adolescents from Abruzzo, Italy]. Annali di igiene: medicina preventiva e di comunità, 2005, 17: 419-431.

[27] Hajian-Tilaki KO., Sajjadi P. and Razavi1 A. Prevalence of overweight and obesity and associated risk factors in urban primary-school children in Babol, Islamic Republic of Iran Eastern Mediterranean Health Journal Past Issues, 2011(17)2: 109-114.

[28] Tabatabaei M. [Prevalence of underweight, overweight and obesity in primary school children of Ahvaz city (Iran)]. In: Proceeding of the 9th Iranian Nutritional Congress, Tabriz University (Iran), 2006:117.

[29] Krassas GE, Tsametis C, Baleki V, Constantinidis T, Unluhizarci K, Kurtoglu S and Kelestimur F. Prevalence of overweight and obesity among children and adolescents in Thessaloniki-Greece and Kayseri- Turkey.PediatricEndocrinology Reviews; PER, 2004, 1(Suppl. 3): 460-464.

[30] Langendijk G, Wellings S, van Wyk M, Thompson SJ, McComb J and Chusilp K. The prevalence of childhood obesity in primary school children in urban Khon Kaen, northeast Thailand. Asia Pacific Journal of Clinical Nutrition, 2003, 12: 66-72.

[31] Huffman, F.G, Kanikireddy, S. and Patel M. Parenthood-a contributing factor to childhood obesity. International Journal of Environ mental research and public health, 2010; 7 (7) 2800-2810.

[32] Chrzanowska M., Koziel S. and Ulijaszek S. Changes in BMI and the prevalence of overweight and obesity in children and adolescents in Cracow, Poland, 1971-2000. Economics and human biology, 2007; 5; 370-378.

[33] Yamamah G., Hassan N., El- masry S., Salama E. and Shouman M. South Sinai growth charts of children and adolescents. Journal of American science, 2010; 6(10).

[34] Oken E. and Gillman M. Fetal origins of obesity. Obes res 2003; 11: 496-506.

[35] Martinez E, Allen B, Galal O, and Ortega C. Overweight and obesity status among adolescents from Mexico and Egypt. Archives of medical research, 2006; 37: 535-42.

[36] Khalil I.F. Obesity, community medicine. pp. 190-93. Dar el-tibaa el-kawmeya, Cairo, Egypt. 1999.

[37] Fernald L. Socio-economic status and body mass index in lowincome Mexican adults. Social science and medicine, 2007; 64: 2030-42.

[38] McCormack GR1, Hawe P, Perry R and Blackstaffe A. Assoications between familial affiluence and obesity risk behaviours among children. Paediatrics and Child Health, 2011; 16: 19-24.

[39] Wang Y, Chen HJ, Shaikh S and Mathur P. Obesity becoming a public health problem in India examine the shift from under-to overnultrition problems over time. Obesity Reviews, 2009; 10: 456-474.

[40] Warraich HJ1, Javed F, Faraz-Ul- Haq M, Khawaja FB and Saleem S. Prevalence of obesity in school-going children of Karachi. PLOS ONE, 2009; 4:e4816.

[41] Askesode FA and Ajibode HA. Prevalence of obesity among Nigerian school children. Soc Science Med. 1983; 17: 107-11.

[42] Doak C.M., Visscher T.L.S., Rendersand C.M. and Siedell J.C. The prevention of overweight and obesity in children and adolescents: a review of interventions and programmes, 2002; 5: 215-21.

[43] Zoumas-Morse C, Rock CL, Sobo EJ and Neuhourser ML. Children Patterns of macronutrients intake and associations with restaurant and home eating. J Am Diet Assoc, 2001; 101: 923-25.

[44] Vihjalmsson R and Thorlindsson. T. Factors related to physical activity: A study of adolescents. Social Science Medicine, 1998; 47: 665-75.

[45] Taylor WC, Blair SN, Cummings SS, WUN CC and Malina RM. Childhood and adolescent model and recommendations for future research, 2001; Obes Rev. ;2:159-71.

[46] Davison KK and Birch LL. Childhood overweight: a contextual model and recommendations for future research, 2001; Obese Rev.; 2: 159-71. 
[47] Parsons TJ, Power C, Logan S and Summerbell CD. Childhood predictors of adult obesity: a systematic review. Int J Obes Relat Metab Disord, 1999; 23(Suppl 8): S1-S107.

[48] Dubois L, Farmer A, Girard M and Peterson K. Regular sugarsweetened beverage consumption between meals increases risk of overweight among preschool-aged children. J Am Diet Assoc.2007; 107: 924-934.

[49] Dubois L, Farmer A, Girard M and Peterson K. Social factors and television use during meals and snacks is associated with higher BMI among pre-school children. Public Health Nutr. 2008; 11: 1267-1279.

[50] Al-Kloub MI, Al-Hassan MA and Froelicher ES. Predictors of obesity in school-aged Jordanian adolescents. Int. J. Nurs. Pract. 2010; 16: 397-405.

[51] Utter J, Scragg R, Mhurchu CN and Schaaf D. At-home breakfast consumption among New Zealand children: associations with body mass index and related nutrition behaviors. J Am Diet Assoc. 2007; 107: 570-576.
[52] Cho S, Dietrich M, Brown CJ, Clark CA and Block G. The effect of Break Fast type an total daily energy intake and body mass index: Results form the thirds National Health and nutrition Examination survey (NHANES III). J Am Coll Natr. 2003; Aug; 22 (4): 296-302.

[53] Hattner JA. The problem is growing: overweight child program and abstracts of the national association of pediatrics Nurse practitioner $25^{\text {th }}$ Annual Conference on pediatrics healthcare. 2004 March 24-27, Dallas, Texas.

[54] Tanagho M.S. Study of prevalence of obesity and its determinants among adolescent school students in Alexandria. Unpublished thesis, M.P.H. Egypt Alexandria: University of Alexandria, HIPH, 2004.

[55] Bereket Gebremichael and Amsale Chere, Prevalence of Childhood Overweight and Obesity and its Determinant Factors Among Elementary School Children in Addis Ababa, Ethiopia: A Cross Sectional Study, 2013. 